\title{
Seismic evidence for uniform crustal accretion along slow-spreading ridges in the equatorial Atlantic Ocean
}

\section{Zhikai Wang ( $\nabla$ zwang@ipgp.fr)}

Institut De Physique Du Globe De Paris https://orcid.org/0000-0003-0852-2658

\section{Satish Singh}

Institut De Physique Du Globe De Paris https://orcid.org/0000-0002-4594-801X

\section{Article}

Keywords:

Posted Date: February 21st, 2022

DOI: https://doi.org/10.21203/rs.3.rs-1366304/v1

License: (c) (i) This work is licensed under a Creative Commons Attribution 4.0 International License.

Read Full License 
1 Seismic evidence for uniform crustal accretion along slow-spreading

2 ridges in the equatorial Atlantic Ocean

$$
\text { Zhikai Wang* and Satish C. Singh }
$$

Institut de Physique du Globe de Paris, 1 rue Jussieu, Paris 75238, France

*Corresponding author: zwang@ipgp.fr

The crustal accretion along mid-ocean ridges is known to be spreading-rate dependent. Along fast-spreading ridges, two-dimensional sheet-like mantle upwelling creates relatively uniform crust. In contrast, the crust formed along slowspreading ridges shows large along-axis thickness variations with thicker crust at segment centres, which is hypothesised to be due a three-dimensional plume-like mantle upwelling with melt focusing to segment centres. Using wide-angle seismic data acquired from the equatorial Atlantic Ocean, we show that the crustal thickness is nearly uniform $(\sim 5.5 \mathrm{~km})$ across five segments for crust formed at the slow-spreading Mid-Atlantic Ridge with age varying from 8 to 70 Ma. The crustal velocities indicate that this crust is predominantly of magmatic origin. We suggest that this uniform magmatic crustal accretion is due to a two-dimensional sheet-like mantle upwelling, contradicting previous hypothesis. Our results also indicate that the lateral extend of magmatic accretion could be used to define the sheet-like mantle upwelling regions beneath the global ridge system. 
22 The oceanic crust covers $\sim 60 \%$ of the Earth's surface and is continuously generated along 23 the $\sim 65,000 \mathrm{~km}$-long divergent plate boundaries at the Mid-Oceanic Ridges (MORs) ${ }^{1}$.

24 The MORs are partitioned into tens to hundreds kilometre-long first-order segments by 25 oceanic transform faults (TFs) ${ }^{1}$. Between two oceanic TFs, these ridge segments are 26 further divided into smaller ridge segments (second-order segments) by non-transform 27 offsets (NTOs) and overlapping spreading centres (OSCs) ${ }^{1}$.

29 The crustal accretion along MORs and the resulting along-axis crustal thickness variation 30 are known to be spreading-rate dependent. At the fast-spreading ridges, such as the East31 Pacific Rise (EPR), the oceanic crust exhibits relatively uniform thickness with a modest 32 crustal thinning $\left(\leq 1.6 \mathrm{~km}\right.$; orange triangles in Fig. 1) at oceanic TFs, NTOs and OSCs ${ }^{2-6}$, 33 interpreted to result from a two-dimensional (2-D) sheet-like mantle upwelling beneath 34 these ridges $^{3}$ and/or rapid ductile flow of hot lower crust along these ridges ${ }^{7}$. In contrast, 35 the studies using gravity data ${ }^{3,8-11}$ collected along the slow-spreading Mid-Atlantic Ridge 36 (MAR) reveal systematically significant reduction (up to 50\%) in crustal thickness from 37 segment centres to the associated distal ends at TFs and NTOs. Crustal thickness 38 estimation using active-source seismic data also shows large and systematic along-axis 39 crustal thickness variations at MAR, where the crust at distal ends could be up to $\sim 3.2-5.7$ $40 \mathrm{~km}$ thinner than that at the segment centres ${ }^{9,}{ }^{12-18}$ (orange dots in Fig. 1). All these 41 observations demonstrate focused magmatic crustal accretions along the slow-spreading 42 ridges, which are interpreted to result from either a three-dimensional (3-D) plume-like 43 mantle upwelling ${ }^{3,8}$ or by a 3-D melt migration to the segment centres at the base of the 44 lithosphere beneath slow-spreading ridges ${ }^{19,20}$. However, these previous studies on MAR 45 are generally concentrated within or close to the spreading centres, sampling only young 46 ( $\leq 2 \mathrm{Ma})$ oceanic crust. In contrast, old oceanic crusts formed along MAR show different 47 patterns of segment-scale crustal thickness variation. For example, although large 48 segment-scale crustal thickness variations are observed for $\sim 5$ and $\sim 65$ Ma old crust in the 49 North Atlantic Ocean ${ }^{17,21,22}$, the crustal thinning is only $\sim 2.8-3.4 \mathrm{~km}$ (blue dots in Fig. 50 1), smaller than those observed along or near ridge axis. For much older crust ( 130-150 $51 \mathrm{Ma})$ in the North Atlantic Ocean, the crustal thinning is very modest ${ }^{23,24}$. A recent study 
52 from the South Atlantic Ocean over 6.6-61.2 Ma crust at $31^{\circ} \mathrm{S}$ shows very little variations

53 in crustal thickness over 40-60 km lateral distance ${ }^{25}$.

55 The plate separation at the slow-spreading ridges is accommodated by two contrasting 56 modes of accretion. For the regions where the melt supply is robust and sufficient, the 57 magmatic accretion creates thick igneous crust. In contrast, for the regions where melt 58 supply is limited, the plate separation is mainly accommodated through tectonic slips 59 along low-angle detachment faults, emplacing lower crustal and upper mantle rocks to 60 the seafloor forming oceanic core complexes (OCCs) and thin $\mathrm{crust}^{26}$.

62 Crustal P-wave velocity (Vp) obtained using wide-angle seismic data can be used to 63 discriminate between these two different modes of crustal accretion. For example, the 64 magmatically accreted crust can be divided into two layers based on their velocities ${ }^{27,28}$. 65 The upper crust (Layer 2) is characterised by a relatively low Vp (4.1-6.5 km/s) but a 66 high vertical velocity gradient $\left(\sim 1-2 \mathrm{~s}^{-1}\right)$ whereas the lower crust (Layer 3$)$ has a high Vp $67(6.5-7.1 \mathrm{~km})$ but a significantly reduced velocity gradient $\left(\sim 0.1-0.2 \mathrm{~s}^{-1}\right)$. This seismic 68 structure has been designated as the 'Penrose model' which equates these layers to an 69 upper crust composed of extrusive basalts and sheeted dyke overlying a gabbroic lower 70 crust $^{1}$. In contrast, the crustal Vp below the OCCs increases rapidly to $>6.5-7.0 \mathrm{~km} / \mathrm{s}$ 71 within $\sim 1.0-2.5 \mathrm{~km}$ depth below the seafloor ${ }^{22,29-33}$, suggesting the presence of lower 72 crustal gabbroic rocks or partially serpentinised peridotite exhumed to shallow depths. 73 However, any interpretation about the crustal structure based only on the Vp model is 74 poorly constrained because of the ambiguity in velocity-lithology relationship. As the Vp 75 increases from $\sim 4.5-5.0 \mathrm{~km} / \mathrm{s}$ for a completely serpentinised peridotite to $\sim 8.0 \mathrm{~km} / \mathrm{s}$ for an 76 unaltered peridotite ${ }^{34,35}$, there is an overlap with the $\mathrm{Vp}(4.1-7.1 \mathrm{~km} / \mathrm{s})$ for magmatic 77 oceanic crust ${ }^{27}$. On the other hand, laboratory measured velocities of rocks from oceanic 78 drillings show that the magmatic crustal rocks (basalt and gabbro) generally have $\mathrm{P}$ and $79 \mathrm{~S}$-wave $(\mathrm{Vs})$ velocity $(\mathrm{Vp} / \mathrm{Vs})$ ratios $<1.9$ at the crustal pressure condition ${ }^{35,36}$ while the $80 \mathrm{Vp} / \mathrm{Vs}$ ratio of serpentinised mantle rocks varies from $\sim 1.78$ to $\sim 2.21$ with increasing 
81 degree of alteration ${ }^{34}$. Therefore, the $\mathrm{Vp} / \mathrm{Vs}$ ratio is a useful physical parameter for

82 constraining the crustal composition ${ }^{37}$, hence the thickness of the crust.

84 Here, we estimate the $\mathrm{Vp}$ and $\mathrm{Vp} / \mathrm{Vs}$ ratio of five segments of the slow-spreading crust 85 covering $\sim 8-70$ Ma lithosphere in the equatorial Atlantic Ocean (Figs. 2a) using an 86 active-source seismic refraction dataset to characterize the nature of the oceanic crust and 87 to shed light on the crustal accretion and mantle upwelling processes along slow88 spreading ridges.

90 The equatorial Atlantic Ocean started opening $\sim 100-140 \mathrm{Ma}^{38,39}$. The average half91 spreading rate varied several times in the past between 15 and $25 \mathrm{~mm} / \mathrm{yr}$, and the current 92 half-spreading rate is $\sim 16 \mathrm{~mm} / \mathrm{yr}^{40}$ (Fig. 2b), hence the equatorial MAR can be classified 93 as a slow-spreading ridge ${ }^{41}$. In this region, three east-west striking mega-transforms (St. 94 Paul, Romanche and Chain TFs) offset the MAR by a total of $\sim 1,800 \mathrm{~km}$ (Fig. 2a). The 95 St. Paul TF system encompasses four TFs interrupted by three intra-transform ridge 96 segments, generating a total offset of $\sim 600 \mathrm{~km}^{42}$. Away from its eastern ridge-transform 97 intersections (RTI), the traces of the four TFs persist up to $20 \mathrm{Ma}$ of seafloor and then 98 only two traces of the TFs can be identified on the older seafloor ${ }^{43}$. Our seismic profile 99 transects the St. Paul fracture zone (FZ) where the crustal age is $\sim 70 \mathrm{Ma}$ in the north and $100 \sim 40 \mathrm{Ma}$ in the south. The Romanche TF offsets the MAR by $\sim 880 \mathrm{~km}^{44}$. The portion of 101 the Romanche TF crossed by our seismic profile is characterized by a $\sim 6 \mathrm{~km}$-deep and $102 \sim 40 \mathrm{~km}$-wide valley with bounding walls shallowing to $<3 \mathrm{~km}$ depth below sea level. The 103 age contrast along our profile is $\sim 32$ Ma across the Romanche TF, with crustal age of $\sim 40$ $104 \mathrm{Ma}$ in the north and $\sim 8 \mathrm{Ma}$ in the south. Our seismic profile crosses the Chain FZ at $\sim 160$ $105 \mathrm{~km}$ west of the western Chain RTI, where the crustal age is $\sim 10 \mathrm{Ma}$ in the north and $\sim 24$ $106 \mathrm{Ma}$ in the south. Along our profile, the Chain FZ is characterized by a $\sim 10 \mathrm{~km}$-wide 107 sedimentary basin, which is bounded by a transverse ridge to the south and shows gradual 108 seafloor shallowing to the north ${ }^{45}$. An oblique pseudofault is observed between the Chain 
and Charcot FZs, intersecting the Chain FZ at $\sim 46 \mathrm{Ma}$ to the west and NTO within the $\sim 17 \mathrm{Ma}^{45}$, showing a typical half $\mathrm{V}$-shaped feature on the seafloor.

The seismic data used in this study was acquired in 2018 during the ILAB-SPARC experiment ${ }^{42,44,45}$. The $\sim 855 \mathrm{~km}$-long seismic profile is nearly parallel to the ridge axis in an approximately N-S direction, starting just north of the Charcot FZ in the south and extending to $\sim 230 \mathrm{~km}$ distance north of the St. Paul FZ (Fig. 2a). Fifty OBSs were deployed along the $\sim 700 \mathrm{~km}$ part of the profile at average $14.2 \mathrm{~km}$ interval. An airgunarray of 16 guns with a total volume of 4990 cubic inches was towed at $10 \mathrm{~m}$ depth below sea level and was fired every $300 \mathrm{~m}$. Both P and S-wave arrivals were hand-picked on the pressure data recorded by hydrophones (Supplementary Figs. 1 and 2) and were inverted using a 2-D ray-based travel time tomographic method ${ }^{2,46}$ to obtain Vp and Vs models (Figs. 3a,b; See Methods). Then the crustal and upper mantle Vp/Vs ratios (Fig. 3c) were calculated using the inverted Vp and Vs models. Using these results, we first determine the predominant mechanism of crustal formation for each crustal segment and then analyse the segment-scale crustal thickness variations to understand the crustal accretion process along the slow-spreading MAR in the equatorial region.

\section{Results}

\section{Magmatically accreted crust versus tectonically controlled crust}

To determine the dominant mode of crustal accretion, we use a $\mathrm{Vp} / \mathrm{Vs}$ ratio of 1.9 as an indicator $^{37}$ to discriminate between the magmatic crust $(\mathrm{Vp} / \mathrm{Vs}<1.9)$ and the serpentinised peridotite $(\mathrm{Vp} / \mathrm{Vs}>1.9)$ at crustal depth. The tomographic results show two different types of crustal $\mathrm{Vp}$ structures for the five ridge segments characterized by distinct crustal $\mathrm{Vp} / \mathrm{Vs}$ ratios (Fig 3), which can be interpreted resulting from two different modes of crustal accretion: magmatic accretion and tectonic accretion along detachment fault. 
The oceanic crust within the Segments 1, 2, 3-S, 4 and 5 exhibits a two-layered Vp structure (Figs. 3a and 4a) characterized by distinct vertical Vp gradients. Using the vertical Vp gradient of $0.5 \mathrm{~s}^{-1}$ to define the boundary between the upper and lower crust ${ }^{47}$, the upper crust is $\sim 1.9-2.3 \mathrm{~km}$ thick showing high vertical $\mathrm{Vp}$ gradients of $\sim 0.66-0.80 \mathrm{~s}^{-1}$ (Supplementary Table 1). Beneath the upper crust, the Vp in the lower crust, which is $\sim 3.1-3.5 \mathrm{~km}$ thick, increases at a much-reduced velocity gradient of $\sim 0.13-0.17 \mathrm{~s}^{-1}$ (Supplementary Table 1). The maximum crustal Vp within these segments is generally $<7.2 \mathrm{~km} / \mathrm{s}$ (Figs. 3a and 4a). These crustal Vp structures fall in the velocity range typical for older slow-spreading magmatic oceanic crust ${ }^{27,28}$ (Fig. 4a). These crustal segments are generally characterized by crustal $\mathrm{Vp} / \mathrm{Vs}$ ratios less than 1.9 (Fig. 3c), indicative of basaltic and gabbroic rocks in the crust ${ }^{37}$. The Moho, the crust/mantle boundary, is well constrained using Moho wide-angle reflections. A rapid increase from crustal velocities to mantle velocities across the Moho is observed throughout these ridge segments, where the Vp increases abruptly by $\sim 0.7-0.9 \mathrm{~km} / \mathrm{s}$ across the Moho (Figs. 3a and $4 \mathrm{a}$ ). Both the $\mathrm{Vp}$ and $\mathrm{Vp} / \mathrm{Vs}$ ratio models support that the observed two-layered crustal velocity structure can be explained by the 'Penrose' model $^{1}$ indicating a predominantly magmatic accretion of crust throughout these ridge segments.

In contrast, the Segment 3-N between 340 and $400 \mathrm{~km}$ profile distance immediately south of the Romanche TF shows a rapid increase in the crustal Vp of $\sim 7.7 \mathrm{~km} / \mathrm{s}$ at $\sim 2.2 \mathrm{~km}$ sub-basement depth (Figs. 3a and 4b). This anomalously high Vp exceeds the typical velocity for the normal oceanic crust $\left(<7.2 \mathrm{~km} / \mathrm{s}^{27,28}\right)$. Conversely, the upper crustal Vs within Segment 3-N shows a similar velocity-depth variation as that within Segment 3-S. The crustal Vp/Vs ratios are larger than 1.9 in the upper crust (Fig. 3c), suggesting the presence of serpentinised peridotite, indicative of predominantly tectonic extensions ${ }^{37}$. The rapid increase in the crustal $\mathrm{Vp}$ with depth can be interpreted as a gradual decrease in mantle serpentinisation. Assuming a Vp of $8.0 \mathrm{~km} / \mathrm{s}$ and $5.0 \mathrm{~km} / \mathrm{s}$ for $0 \%$ and $100 \%$ serpentinised peridotite ${ }^{34,35}$, respectively, the observed $\sim 7.7 \mathrm{~km} / \mathrm{s}$ velocities represent $\sim 10 \%$ of mantle serpentinisation at $\sim 2.2 \mathrm{~km}$ sub-basement depth. A recent petrological study of dredged rocks from the eastern Romanche RTI region identified fragments of old OCCs 
on the south flank of the Romanche $\mathrm{TF}^{48}$. This is consistent with our interpretation that immediately south of the Romanche TF, the plate separation is mainly accommodated by tectonic slip along detachment faults.

\section{Intra-segment crustal thickness variation within magmatic segments}

The thickness of the igneous crust is defined as the thickness between the top basement and the seismically constrained Moho. Based on the crustal $\mathrm{Vp}$ and $\mathrm{Vp} / \mathrm{Vs}$ structures, Segments 1, 2, 3-S, 4 and 5 (Fig. 3) are interpreted as consisting of magmatic crust. The average crustal thicknesses within these magmatic segments are $~ 5.4-5.6 \mathrm{~km}$ (Fig. 5), consistent with some previous estimates in this region ${ }^{42,44,45}$. The average crustal thicknesses of the five segments are $\sim 500-700 \mathrm{~m}$ thinner than the global average of the old (>7.5 Ma) slow-spreading crust but still fall into the standard deviation $(6.1 \pm 1.0$ $\mathrm{km}^{27}$ ). The oceanic crust shows a slight thinning at FZ, TF and pseudofault regions, which is confined in a narrow zone in the vicinity of the trough of these tectonic discontinuities (Fig. 5 and blue squares in Fig. 1). At the southern end of Segment 1, the crust thins by $\sim 600 \mathrm{~m}$ at the centre of the northern St. Paul FZ valley over $<5 \mathrm{~km}$ distance and the average crustal thickness within the St. Paul FZ is only 200-400 m thinner than the average thickness of the adjacent segments ${ }^{42}$ (Figs. 5a,b). The crust within the $\sim 20$ $\mathrm{km}$-wide Romanche transform valley is $\sim 5.1 \mathrm{~km}$ thick on average, which is only $\sim 500 \mathrm{~m}$ thinner than the average of Segment 2 to the north (Fig. 5b). Though the crustal Vp/Vs ratio is not constrained, Gregory et al. ${ }^{44}$ argued the thick crust at the Romanche transform zone is likely composed of fractured mafic rocks, and hence can support the supershear rupture during the $2016 M_{\mathrm{w}} 7.1$ earthquake $^{49}$. The crust beneath the $\sim 10 \mathrm{~km}$-wide Chain FZ trough has an average thickness of $\sim 4.7 \mathrm{~km}$, which is $\sim 700-800 \mathrm{~m}$ thinner than the averages of the adjacent Segments 3-S and 4 (Figs. 5c,d). The thinnest crust within the Chain FZ trough is $\sim 4.1 \mathrm{~km}$, which is $\sim 500 \mathrm{~m}$ thinner than that measured in ref. (45). The average crustal thickness within the pseudo-fault trough is $\sim 5.2 \mathrm{~km}$ with the thinnest crust of $\sim 4.8 \mathrm{~km}$ thick, which is $\sim 200-400 \mathrm{~m}$ thinner than the adjacent segments (Fig. 5e). The crustal Vp and Vs (Figs. 3a,b) are lower at the FZ, TF and pseudofault regions relative to the surrounding crust, which could be due to the presence of faults and fluids. 
197 We take the standard deviation of mean crustal thickness as a measure of the intra198 segment crustal thickness variation ${ }^{13,14,25,50,51}$. The standard deviations of the mean 199 crustal thickness within these five segments are 0.1-0.4 km (Fig. 5), which is much 200 smaller than those $\left(\geqslant 1.0 \mathrm{~km}^{13,14}\right)$ for other MAR segments where large along-axis 201 crustal thinning is observed. However, they are very close to those $\left(\leqslant 0.3 \mathrm{~km}^{50,51}\right)$ 202 observed along the fast-spreading EPR, suggesting relatively uniform crustal thickness 203 within these segments. Though the locations of NTOs are difficult to identify over the old 204 crust in this region, there is no evidence supporting thicker crust at the segment centre 205 and $>2.8 \mathrm{~km}$ gradual crustal thinning towards the tectonic discontinuities within any of 206 the five segments. The relatively low crustal Vp at the FZ, TF and pseudofault regions 207 (Fig. 3a) indicates the thick crust at these tectonic discontinuities is not due to the 208 inherent positive velocity-Moho depth trade-off in the travel time tomography ${ }^{46}$. A 209 Monte-Carlo based uncertainty analysis yields the variance in the Moho depth of <330 m 210 (see Methods; Supplementary Fig. 5b), demonstrating that the observed uniform crust 211 does not result from a particular starting $\mathrm{Vp}$ model used in tomography. The 212 checkerboard tests (see Methods; Supplementary Figs. 6 and 7) demonstrate that the used 213 tomography method can recover $\sim 1.5-2.0 \mathrm{~km}$ crustal thickness variations when the real 214 variations in crustal thickness are $\sim 2.5-3.0 \mathrm{~km}$ over $\sim 70 \mathrm{~km}$ lateral distance. These tests 215 demonstrate that the observed uniform crust within these five ridge segments is real.

\section{Discussions}

218 Most of previous studies using gravity and seismic data collected on the slow-spreading 219 MAR reveal systematic and significant along-axis reduction in crustal thickness from the 220 centre of segments towards the oceanic TFs, FZs and NTOs ${ }^{3,8-18,21,22}$, suggesting a 3-D 221 plume-like mantle upwelling ${ }^{3,8}$ and/or a focused melt concentration to segment centres ${ }^{19}$, $222{ }^{20}$ beneath the slow-spreading ridges. However, the five segments with predominantly 223 magmatically accreted crust in the equatorial Atlantic Ocean show slightly thin crust with 224 little intra-segment crustal thickness variation throughout each segment (Figs. 1 and 5), 
225 which is remarkably different from the most previous observations in the Atlantic Ocean 226 but similar to some recent observations on 6.6-61.2 Ma oceanic crust at $31^{\circ} \mathrm{S}$ in the South 227 Atlantic Ocean ${ }^{25}$. The crust within these segments is either (1) originally formed 228 uniformly at the ridge axis, or (2) has been modified after crustal formation by tectonic 229 extension/stretching during the amagmatic period, or (3) by a second-stage crustal 230 accretion at RTIs. Here, we analyse all these hypotheses and propose the best mechanism 231 that explains the formation of uniformly thick crust in the equatorial Atlantic Ocean.

233 The tectonic extension and stretching account for $\sim 10 \%$ of plate separation at the slow234 spreading ridges ${ }^{52,53}$, which could thin the oceanic crust. The fault spacing and heave are 235 generally larger at segment ends than at segment centres of slow-spreading ridges, 236 indicating more tectonic extension should occur at segment ends due to the decreasing 237 magma supply ${ }^{54}$. If the focused mantle upwelling and melt supply did occur at the time of 238 crustal formation, the tectonic extension and stretching would increase the magnitude of 239 the intra-segment crustal thinning ${ }^{10,54}$ within these five ridge segments, rather than 240 diminish this trend. Furthermore, numerical modelling shows that the gravity anomaly 241 caused by tectonic faulting increases with increasing fault throw and spacing ${ }^{55}$, further 242 supporting the idea that the tectonic extension and stretching will enhance the along-axis 243 variation in crustal thickness. All the evidence demonstrates that the tectonic extension 244 and stretching cannot explain the uniform crust observed along our profile.

246 Some recent studies indicate that the crust at oceanic TF can get augmented by a second 247 stage of magmatic accretion at $\mathrm{RTI}^{45,56}$. This second-stage crustal accretion at RTIs could 248 laterally emplace dykes at the segment ends and into the transform valley ${ }^{45}$, forming $\mathrm{J}$ 249 shaped structures on the seafloor and thickening the crust. However, the gravity data 250 reveal a $\sim 5 \mathrm{~km}$-thick crust within the Chain transform zone ${ }^{57}$, which is comparable with 251 the average $\sim 5.1 \mathrm{~km}$-thick crust within the Chain FZ trough along our profile (Fig. 5c). 252 Although we do not have any information about the crustal thickness for the Romanche 253 FZ, the crust within the Romanche TF has similar thickness to those within St. Paul and 
254 Chain FZs along our profile (Fig 5). These observations suggest the second-stage 255 magmatic accretion may have limited augmentation to the crust at RTIs. Furthermore, the J-shaped structures have very short extensions over the old ocean floor ${ }^{56}$, suggesting the second-stage crustal augmentation occurs within a limited region in the vicinity of the 258 RTI. Thus, the second-stage magmatic accretion at RTIs is not likely to change the segment-scale variations in the crustal thickness.

261 Another possibility is that the uniform crust might reflect the patterns of crustal and 262 mantle flows and the melt migration along the ridge axis at the time of crustal formation. 263 The slow-spreading ( $10 \mathrm{~mm} / \mathrm{yr}$ half-spreading rate) Reykjanes Ridge in the North 264 Atlantic Ocean produces 8-10 km-thick crust showing an absence of significant along265 axis variation in thickness ${ }^{58}$. This is interpreted to be due to a rapid ductile flow within 266 the hot lower crust because of the influence of the Iceland hotspot ${ }^{7}$. Though the ridge 267 between $5^{\circ} \mathrm{N}$ and the St. Paul TF is suggested to be influenced by the Sierra Leone 268 plume ${ }^{59,60}$, the crustal thicknesses north and south of the St. Paul FZ are similar, ruling 269 out any significant influence of the thermal anomaly to crustal accretion in our study area. 270 Furthermore, the average crustal thickness of 5.4-5.6 km is not thick enough, and hence 271 not hot enough to enable rapid ductile flow in the lower crust. On the other hand, a 3-D 272 diapiric mantle upwelling would produce a large along-axis variation in crustal thickness 3 , $273^{8}$, which is inconsistent with our observations of the five crustal segments studied here.

275 Finally, the relatively uniform crustal thickness observed in the equatorial Atlantic Ocean 276 suggests a relatively uniform (nearly 2-D) mantle upwelling beneath the ridge axis at the 277 time of the crustal accretion (Fig. 6), contradicting the previously proposed 3-D plume278 like mantle upwelling model for the slow-spreading ridges ${ }^{8}$ based on the observations 279 from the North and South Atlantic Ocean, instead it is more similar to the uniform mantle 280 flow pattern occurring at the fast-spreading ridges ${ }^{3}$. The petrological studies of basaltic 281 glasses dredged along the equatorial MAR between the St. Paul and Charcot TFs show a 282 long-wavelength trend $(\sim 600 \mathrm{~km})$ in the mantle potential temperature, the mean degree of 
partial melting and the maximum depth of the decompression melting. This longwavelength trend is independent of the offset and the location of TFs ${ }^{59,60}$. While north of the St. Paul TF to $\sim 5^{\circ} \mathrm{N}$, the mantle potential temperature, the initial depth and the mean degree of mantle melting have little variations over $\sim 400 \mathrm{~km}$ lateral distance due to the influence of the Sierra Leone plume ${ }^{59,60}$. These observations suggest that the extent of mantle melting and mantle isotherms are not significantly suppressed approaching TFs and NTOs as required in the 3-D diapiric mantle upwelling ${ }^{3,8}$, supporting a relatively uniform mantle upwelling in the study region.

The lithosphere-asthenosphere boundary beneath the slow-spreading ridges is expected to 293 progressively deepen from the segment centre towards the oceanic $\mathrm{TFs}^{61}$ due to the juxtaposition of ridge axis with cold lithosphere. The lithospheric thinning away from the TFs towards the centre of segments would shallow the top surface of the melting region, and subsequently enhance the melting at the centre of the ridge segment and produce a thick crust. Magde et al. ${ }^{19,20}$ argued that the segment-scale crustal thickness variations observed at the slow-spreading MAR between $33^{\circ} \mathrm{N}$ and $35^{\circ} \mathrm{N}$ are primarily produced by the focused melt migration to the centre of segments along the slope of the top surface of the melting region, though the mantle upwelling is roughly uniform. In our study region, however, the basaltic glasses dredged from the vicinities of the western RTI of the St. Paul TF, the eastern RTIs of the Romanche and Chain TFs show large local geochemical and isotopic dispersions, suggesting the melt did not pool and mix in the magma chamber but segregated and erupted rapidly from the mantle ${ }^{59}$. This implies that the melt would migrate vertically and rapidly beneath the ridge axis in the equatorial Atlantic Ocean (Fig. 6), rather than focusing to the segment centres before eruption. The nearly 2-D sheet-like mantle upwelling together with nearly vertical melt migration and rapid eruption would facilitate the formation of relatively uniform crust along the ridge axis at the time these five crustal segments were formed. Although a possible existence of a relatively uniform mantle upwelling can be made on the petrological observations along the present-day ridge axis in the equatorial Atlantic Ocean, our results indicate that this process has persisted over the last $70 \mathrm{Myr}$. 
314 The observed uniformity in crustal thickness within a second-order ridge segment 315 between the Rio Grande and Cox FZs in the South Atlantic Ocean is suggested to be 316 related to a long first-order ridge segment $(\sim 320-350 \mathrm{~km})$ facilitating large-scale mantle 317 upwelling ${ }^{25}$. To investigate the influence of the first-order ridge segment length on the 318 crustal accretion, we compiled the maximum crustal thickness variation between the 319 centre and ends of second-order ridge segments and the length of the corresponding first320 order ridge segments in the Atlantic Ocean (Fig. 7). Our compilation demonstrates that 321 there is no positive or negative correlation between the first-order segment lengths and 322 the crustal thickness variations. For example, the $220 \mathrm{~km}$-long first-order segment 323 between the Hayes and Oceanographer TFs shows a maximum of 2.8-4.3 km along-axis 324 crustal thickness variations over the 0-5 Ma crust ${ }^{13,14,17}$ while the $\sim 800 \mathrm{~km}$-long segment 325 between the Kane and Atlantis TFs shows a maximum crustal thickness variation of 3.5 $326 \mathrm{~km}$ along the ridge axis ${ }^{8}$. The lengths of the first-order ridge segments in the equatorial 327 Atlantic Ocean are similar to that of the segment between the Hayes and Oceanographer 328 TFs, but relatively uniform crust is observed. Lin et al. ${ }^{8}$ and Detrick et al. ${ }^{10}$ argued that at 329 the slow-spreading ridges, the magnitude of the along-axis crustal thickness variation 330 within a second-order ridge segment is positively correlated with the length of the 331 second-order segment. We cannot identify the locations of the fossil NTOs (except the 332 pseudofault between the Chain and Charcot FZs) along the seismic profile ${ }^{43}$, but the 333 present-day spreading centres in the equatorial Atlantic Ocean have similar second-order 334 segment length (for example ref. 45) as those observed in other regions in the Atlantic 335 Ocean. We therefore argue that the lengths of first- and second-order ridge segments have 336 no influence on the crustal accretion process.

338 We envisage that the formation of the uniform crust might be associated with the brittle 339 mantle weakening and hydrous mantle melting at the transform zone and the enhanced 340 hydrothermal circulations on the spreading centres. By considering a more realistic brittle 341 mantle weakening, Behn et al. ${ }^{62}$ argued the thermal structure of the transform zone is 342 much warmer than predicted from the half-space cooling model, which can better fit the 
343 depth of seismicity on the oceanic TFs. Their modelling also demonstrates an enhanced 344 mantle upwelling along the transform zone and a much thinner lithosphere at the transform zone, especially at the centre of the transform, than estimated in previous 346 studies using simplified rheologic laws. The base of the lithosphere at the transform zone 347 can be further uplifted by the low-temperature hydrous mantle melting due to the presence of water (Wang et al., 2022). Meanwhile, the lithosphere beneath the ridge axis in the equatorial Atlantic Ocean is imaged to be thickened due to the enhanced hydrothermal cooling ${ }^{63,64}$. The combined effect of all these processes could significantly decrease the cold edge effect of large oceanic TF, leading to a relatively flat isotherm (lithospheric base) beneath the ridge axis with only a slight deepening of the lithospheric 353 base in the vicinity of the transform zone. Using the crustal thickness inferred from 354 gravity data, Detrick et al. ${ }^{10}$ argued that the magnitude of the along-axis crustal thinning is approximately proportional to the offset of the adjacent TF. However, only three oceanic TFs of length $<120 \mathrm{~km}$ are investigated in their studies, which are much shorter than the three mega-transforms $(\sim 300-880 \mathrm{~km})$ in the equatorial Atlantic Ocean. In contrast, the compilation of crustal thickness variations (Fig. 8) inferred from activesource seismic data demonstrate that there is no positive correlation between the magnitude of the along-axis crustal thickness variation and the length of the adjacent TF or NTO. The magnitude of the crustal thickness variation is more scattered and larger when the adjacent TF or NTO is short but is smaller for longer TFs. This suggests the mega-transform could facilitate a stable 2-D sheet-like mantle upwelling and a relatively uniform crustal accretion along the slow-spreading ridges.

The tectonic fabric of the ocean basin also reflects the different magmatic accretion patterns (focused or uniform) along the MAR. Though NTOs are observed on the ridge axis in the equatorial Atlantic Ocean ${ }^{43,45}$, the seafloor fabric ${ }^{43}$ indicates that these NTOs are more transient features with nearly no imprint away from the ridge axis, suggesting that the base of the lithosphere beneath these short-lived NTOs does not deepen much and remains nearly flat, hindering the melt focusing towards segment centres and leading to a relatively uniform crustal accretion. 
374 The equatorial Atlantic Ocean has been suggested to be a cold spot ${ }^{60,65}$, where the 375 mantle temperature is at least $150^{\circ} \mathrm{C}$ lower than that beneath other parts of the $\mathrm{MAR}^{65}$. 376 Our results suggest that the dominantly uniform magmatic accretion can occur not only at 377 fast-spreading ridges ${ }^{3}$ and at slow-spreading ridges influenced by hotspots ${ }^{7}$, but can also 378 occur at slow-spreading ridges influenced by cold spots over a long geological period. 379 The average crustal thicknesses of the five magmatic segments in the equatorial Atlantic 380 Ocean are thinner than the global average ${ }^{27}$, which can be attributed to a low degree of 381 mantle melting due to the cold mantle ${ }^{59,60}$. Studies using bathymetry and seismic 382 refraction datasets found that the detachment fault accommodating plate separation 383 occurs along $~ 50 \%$ of the ridge axis in the North Atlantic Ocean ${ }^{22,66}$. However, along our 384 seismic profile, the magmatically accreted crustal segments comprise $>90 \%$ of the total 385 profile length, which is much higher than the previous estimates for the slow-spreading 386 ridges, suggesting that the mode of accretion plays a more important role in defining the 387 2-D versus 3-D mantle upwelling, and the lateral extent of the magmatic accretion could 388 be used to map the 2-D sheet-like mantle upwelling regions along the global spreading 389 ridge system. 


\section{Methods}

392 Seismic data analysis and travel time picking. The travel times of crustal refractions $393(\mathrm{Pg})$, wide-angle reflections from the Moho (PmP) and the mantle refractions (Pn) have 394 been hand-picked on the seismic data after band-pass filtering (4-15 Hz for Pn arrivals 395 and 4-20 Hz for Pg, PmP and S-wave arrivals). The Pg phases are identified as first 396 arrivals outside of the water wave on 50 OBSs from $\sim 4$ to $\sim 35 \mathrm{~km}$ offsets (Supplementary 397 Fig. 1, orange dots). The picking uncertainty of the Pg arrivals varies between 30 and 50 398 ms. The Pn phases are identified from $\sim 15-35$ to $\sim 250 \mathrm{~km}$ offsets for most OBSs (Wang 399 et al., 2022). In this work, only the Pn arrivals within $40 \mathrm{~km}$ offset are shown 400 (Supplementary Fig. 1, blue dots). The picking uncertainty of the Pn arrivals varies 401 between 45 and $100 \mathrm{~ms}$. The PmP phases reflected off the Moho are identified at 10-40 $402 \mathrm{~km}$ offsets as second arrivals after the Pg and Pn phases (Supplementary Fig. 1, cyan 403 dots). The picking uncertainty of the PmP arrivals is 50 or $70 \mathrm{~ms}$.

The crustal and mantle S-wave arrivals are observed on seismic data recorded by 43 OBSs as secondary arrivals after the P-wave first arrivals and codas (Supplementary Fig. 2). In this study, we use $\mathrm{Sg}, \mathrm{SmS}$ and $\mathrm{Sn}$ to represent the $\mathrm{S}$-wave crustal refractions, Moho reflections and mantle refractions, respectively. We first pick the S-wave arrivals that have high signal-to-noise ratios using the trace-to-trace coherency of phases and then we invert these picks to obtain a smooth velocity model for the crust and uppermost mantle. Synthetic travel times of S-wave phases are modelled using this smooth velocity 412 model, which is then used as a guide to identify and pick more $\mathrm{S}$-wave arrivals that have 413 low signal-to-noise ratios ${ }^{25,67}$. The Sg arrivals are identified and picked between 5 and 35 $414 \mathrm{~km}$ offsets (Supplementary Fig. 2, orange dots) with picking uncertainty ranging from 30 415 to $60 \mathrm{~ms}$. The $\mathrm{SmS}$ phases are picked at offset ranges similar to the PmP arrivals 416 (Supplementary Fig. 2, cyan dots), with picking uncertainty of 60-80 ms. The Sn arrivals 417 are picked on 38 OBSs (Supplementary Fig. 2, blue dots) with picking uncertainty of 50$418100 \mathrm{~ms}$. 
420 Starting velocity models for travel time tomography. The seafloor depth and sediment

421 thickness along the seismic profile are determined using coincident high-resolution

422 bathymetry data and seismic reflection data ${ }^{44,45}$. The velocities of water and sediment are

423 set to $1.5 \mathrm{~km} / \mathrm{s}$ and $1.86 \mathrm{~km} / \mathrm{s}$ in tomography ${ }^{44,45}$, respectively. The initial crustal $\mathrm{Vp}$

424 model is constructed using a simplified one-dimensional (1-D) velocity profile 44,45

425 hanging from the basement. We introduce a smooth Moho interface into the starting Vp

426 model at $\sim 5.5 \mathrm{~km}$ depth below the basement. The initial structure of the Moho is obtained

427 by smoothing the basement reflector within a $12 \mathrm{~km}$-wide sliding window. The starting

428 mantle Vp model is constructed utilizing a 1-D velocity profile hanged from the smooth

429 Moho, where the mantle Vp increases from $7.8 \mathrm{~km} / \mathrm{s}$ just below the Moho with a vertical

430 velocity gradient of $0.014 \mathrm{~s}^{-1}$ to $20 \mathrm{~km}$ sub-Moho depth and then increases gently

431 (gradient of $0.0035 \mathrm{~s}^{-1}$ ) to the base of the model. The model is $867 \mathrm{~km}$ wide and $90 \mathrm{~km}$

432 deep, and is discretized by $300 \mathrm{~m}$ grid spacing horizontally and $60 \mathrm{~m}$ grid spacing

433 vertically. In this study, we first model and invert the picked travel times of P-wave

434 arrivals to obtain the crustal and mantle $\mathrm{Vp}$. The starting Vs model for inverting the

435 picked travel times of S-wave arrivals is converted from the final Vp model, assuming a

$436 \mathrm{Vp} / \mathrm{Vs}$ ratio of 1.74 for both crust and mantle. The depth of the Moho constrained by the

437 PmP travel times is fixed during the inversion of the travel times of S-wave arrivals.

439 Ray-based travel time modelling and tomography. We model and invert all the picked 440 travel times using a two-dimensional ray-based travel time tomography method ${ }^{2,46}$. The 441 ray paths and travel times of the crustal and mantle arrivals are calculated using the 442 shortest path method ${ }^{68}$. We take a top-down inversion strategy in the tomography of P443 wave arrivals. The Pg arrivals are inverted first to constrain the velocity of the upper crust, 444 followed by a joint inversion of $\mathrm{Pg}$ and PmP arrivals simultaneously to constrain the 445 crustal velocity and the Moho depth. After the joint inversion of Pg and PmP arrivals, we 446 fix the crustal velocity and the Moho depth, and invert the travel times of Pn arrivals only 447 to update the mantle velocity. First- and second-order velocity regularizations are 448 imposed to obtain a smooth velocity model ${ }^{46}$. The regularization parameters are tested 449 and selected in each iteration step to avoid the introduction of artefacts. We use the 
450 standard $\chi^{2}$ value ${ }^{46}$ to measure the mismatch between the modelled and manually picked 451 travel times. We stop the inversion when the $\chi^{2}$ value approaches 1.0 or when non452 physical artefacts appear when further decreasing the $\chi^{2}$ value. The final $\chi^{2}$ value is 1.6 453 for $\mathrm{Pg}$ and $\mathrm{PmP}$ arrivals (Supplementary Fig. 3a) and is 2.2 for $\mathrm{Pn}$ arrivals 454 (Supplementary Fig. 3b). The final RMS misfits ${ }^{46}$ are 42, 65 and $74 \mathrm{~ms}$ for Pg, PmP and 455 Pn arrivals, respectively.

457 The same inversion method and strategies are used in the S-wave tomography, except the 458 Moho depth constrained by the PmP arrivals is fixed in the joint inversion of Sg and $\mathrm{SmS}$ 459 arrivals. Doing so, we have assumed that P- and S-waves share the same boundary 460 between crust and upper mantle. The final $\chi^{2}$ value of combined $\mathrm{Sg}$ and $\mathrm{SmS}$ arrivals is 4611.2 (Supplementary Fig. 3c) and that of Sn arrivals is 1.5 (Supplementary Fig. 3d). The 462 final RMS misfits are 51, 63 and $98 \mathrm{~ms}$ for $\mathrm{Sg}, \mathrm{SmS}$ and $\mathrm{Sn}$ arrivals, respectively.

464 Ray coverage. We use the derivative weight sum (DWS) ${ }^{69}$ to represent the density of ray 465 coverage through the final tomographic models. The DWS of the P-wave arrivals 466 throughout the crust and upper mantle is shown in Supplementary Fig. 4a. The Vp of the 467 upper crust is constrained by dense rays of Pg arrivals between 60 and 760 horizontal 468 distances along the profile, while the lower crust has relatively sparse PmP ray coverage. 469 In the mantle, the Pn arrivals sample the upper mantle down to $\sim 60 \mathrm{~km}$ depth below sea 470 level beneath the Romanche transform valley and the maximum sampled depth gradually 471 decreases to south and north (Wang et al., 2022), but here we only show the model down 472 to $12.5 \mathrm{~km}$ depth (Supplementary Fig. 4a).

474 Supplementary Fig. 4b shows the DWS of S-wave arrivals through the crust and mantle.

475 There is good ray coverage throughout the crust between the horizontal distance $\sim 50$ to $476385 \mathrm{~km}$ and $\sim 460$ to $760 \mathrm{~km}$. The crustal Vs within the Romanche transform zone is not 477 constrained by any $\mathrm{S}$-wave rays. 
478 Monte-Carlo analysis. To assess the accuracy of the crustal and mantle velocities and 479 the Moho depth, we perform Monte-Carlo analyses ${ }^{70}$ starting from different initial models to produce different inverted models and estimate the standard deviation of these models from the mean model to measure the model variance. Here we only describe the details of the Monte-Carlo analysis for crustal Vp and Moho depth. We create 50 starting crustal models by randomly perturbing the minimum and maximum velocity of the onedimensional crustal velocity profile by $\pm 5 \%$ and the initial crustal thickness by $\pm 750 \mathrm{~m}$. These starting crustal models are then inverted using the same tomography algorithm and inversion parameters as described before. These 50 models show similar crustal Vp structure, suggesting the inversion of the picked $\mathrm{Pg}$ and PmP travel times is robust. The variance in the final crustal $\mathrm{Vp}$ model is less than $0.06 \mathrm{~km} / \mathrm{s}$ in the upper crust and is less than $0.18 \mathrm{~km} / \mathrm{s}$ in the lower crust (Supplementary Fig. 5a). The maximum standard deviation of the Moho depth is $\sim 330 \mathrm{~m}$ (Supplementary Fig. 5b). The preferred Moho (Fig. 3a) falls in the standard deviation of the average Moho depth from the Monte-Carlo analysis (see red curve in Supplementary Fig. 5b), and the maximum depth difference between the preferred Moho and the averaged Moho from Monte Carlo analysis is 158 m (Supplementary Fig. 5b).

Similar Monte-Carlo analyses are performed to assess the variance in the crustal Vs. 497 Supplementary Fig. 5c shows the variance of the crustal Vs calculated using 50 final inverted models. For most portion of the crust, the crustal Vs has a variance $<0.06 \mathrm{~km} / \mathrm{s}$, and large variances up to $\sim 0.18 \mathrm{~km} / \mathrm{s}$ are observed around the TF and FZs and at the southern and northern extremity of the model. The variance in the crustal $\mathrm{Vp} / \mathrm{Vs}$ ratio is estimated using the preferred crustal Vp model (Fig. 3a) and the 50 crustal Vs models from the Monte-Carlo analysis. These models are used because they share the same 503 Moho. We calculate the average of the $50 \mathrm{Vp} / \mathrm{Vs}$ models and take the standard deviation 504 as the variance (Supplementary Fig. 5d). The variance in crustal Vp/Vs ratio is $<0.025$ for most portion of the crust, and large variances up to $\sim 0.1$ only occur at local regions where 506 the crustal Vs shows large variance. 
508 Checkerboard tests. We also use the checkerboard test described in ref. (4) to assess the 509 resolution of the final crustal Vp and Vs models. We first perform the checkerboard test 510 to assess the crustal $\mathrm{Vp}$. The checkerboard input models are designed by adding 2-D 511 sinusoidal velocity perturbation of $\pm 8 \%$ into the starting velocity model after slight 512 smoothing. The anomaly size in the checkerboard models is $20 \times 3$ (Supplementary Fig. 6a) 513 and $40 \times 2 \mathrm{~km}$ (Supplementary Fig. 7a), respectively. A sinusoidal perturbation with a 514 half-wavelength of $70 \mathrm{~km}$ and the vertical variation of $1.25 \mathrm{~km}$ was added to the initial 515 Moho to examine the resolvability in the Moho depth ${ }^{4,45}$. The checkerboard models show $516 \sim 2.5-3.0 \mathrm{~km}$ crustal thickness variations over $\sim 70 \mathrm{~km}$ distance (red curves in 517 Supplementary Figs. 6c and 7c). Synthetic seismic travel times are calculated using the 518 checkerboard models and the same receiver-source geometry as the Pg and PmP picks. 519 Some random noise is added to these synthetic picks to represent the picking uncertainty. 520 We invert these synthetic travel times using the same workflow as that for the OBS 521 dataset starting from the same initial model. The results show that velocity anomalies of 522 sizes $20 \times 3$ and $40 \times 2 \mathrm{~km}$ are almost completely resolved (Supplementary Figs. 6b and 7b) 523 with better recovery for anomaly with $20 \times 3 \mathrm{~km}$ size. The crustal thickness within the 524 recovered model shows $\sim 1.5-2.0 \mathrm{~km}$ variations over $\sim 70 \mathrm{~km}$ distance (magenta curve in 525 Supplementary Figs. 6c and 7c), suggesting the tomography method can partially recover 526 the large along-axis variations in crustal thickness. A similar checkerboard test is applied 527 to assess the resolution of crustal Vs model. The checkerboard test shows a higher 528 resolution of the crustal Vs model than the crustal Vp model, where the 8\% velocity 529 anomaly with the $15 \times 3 \mathrm{~km}$ size can be well recovered (Supplementary Fig. 8). Higher 530 resolution is obtained in crustal Vs model because no velocity-Moho depth trade-off 531 occurs in the tomography of S-wave arrivals. 


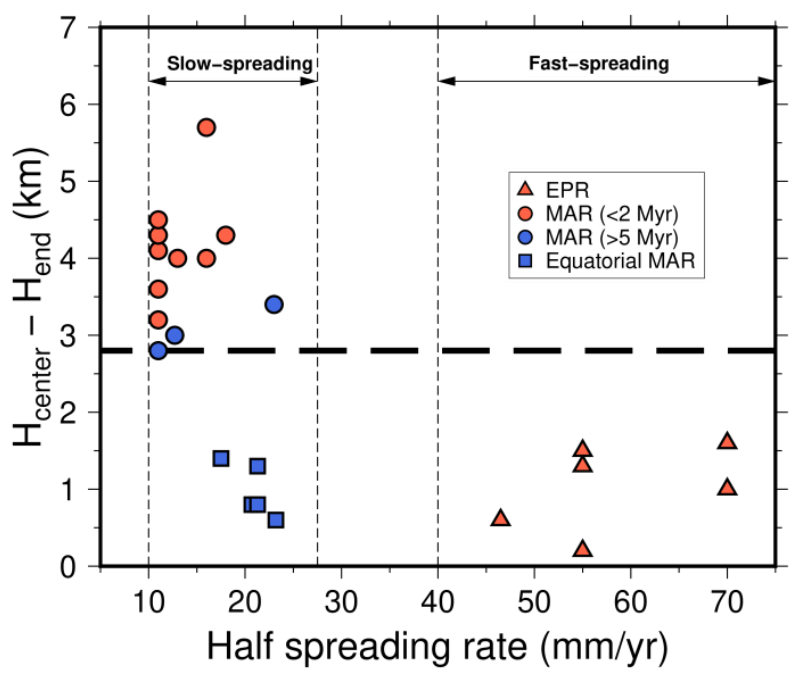

536 Fig. 1 Crustal thickness (H) difference between segment centres and segment ends

537 as a function of spreading rate. Only the crustal thickness constrained by active-source 538 seismic data is considered. The crustal thickness data from the Atlantic Ocean are 539 selected following two criteria: (1) systematically along-axis crustal thinning is observed 540 within the second-order ridge segment and (2) the crustal thicknesses at segment centre 541 and at least one segment end are measured. The blue squares show the crustal thickness 542 reductions at $\mathrm{TF}, \mathrm{FZ}$ and pseudofault region relative to the average crustal thickness of 543 segments obtained in this study. When the crustal thicknesses of both ends of a segment 544 are available, the one with thinner crust is plotted. The crust at the ends of slow-spreading 545 ridges is generally $\geq 2.8 \mathrm{~km}$ (the thick black dashed line) thinner than that at the 546 associated segment centres. Data for EPR, South and North MAR are given in 547 Supplementary Table 2. MAR: Mid-Atlantic Ridge, EPR: East Pacific Rise. The thin 548 dashed vertical lines mark the boundaries of fast- and slow-spreading ridges ${ }^{41}$. The thick 549 dashed horizontal line indicates the boundary between uniform and segment centre 550 focused crust. 
a

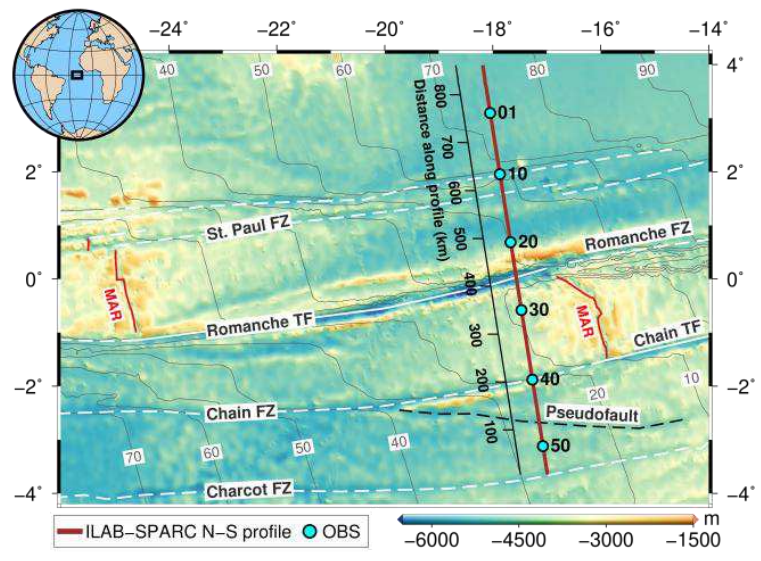

b

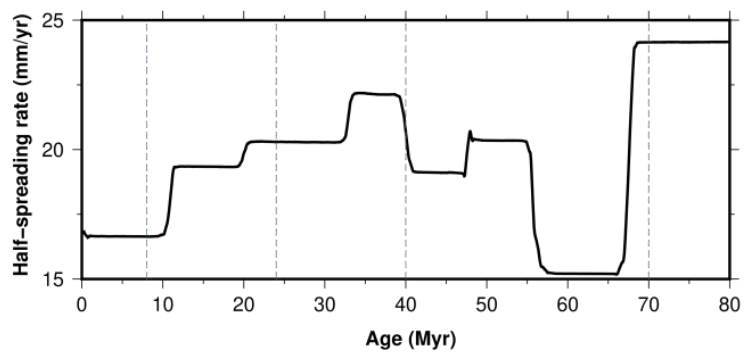

Fig. 2 Study area. a, Bathymetry map showing the Mid-Atlantic Ridge (MAR; red lines), 554 transform faults (TFs; white solid lines) and fracture zones (FZs; white dashed lines) in 555 the equatorial Atlantic Ocean. The seismic profile is shown as a brown line, with the 556 location of every tenth OBS marked by cyan dots. The age of the oceanic crust ${ }^{40}$ is 557 contoured and labelled every 10 Myr. The black rectangle in the globe inset shows the 558 location of the study area. b, Variation in average half-spreading rate ${ }^{40}$ of the equatorial 559 MAR in the past 80 Myr. The dashed blue lines from left to right indicate the ages of 8 , 56024,40 and $70 \mathrm{Myr}$, respectively. As the half-spreading rate varied between 15 and 25 $561 \mathrm{~mm} / \mathrm{yr}$ in the past $80 \mathrm{Myr}$, the equatorial MAR can be classified as the slow-spreading 562 ridge (half-spreading rate between 10 and $27.5 \mathrm{~mm} / \mathrm{yr}^{41}$ ). 
a

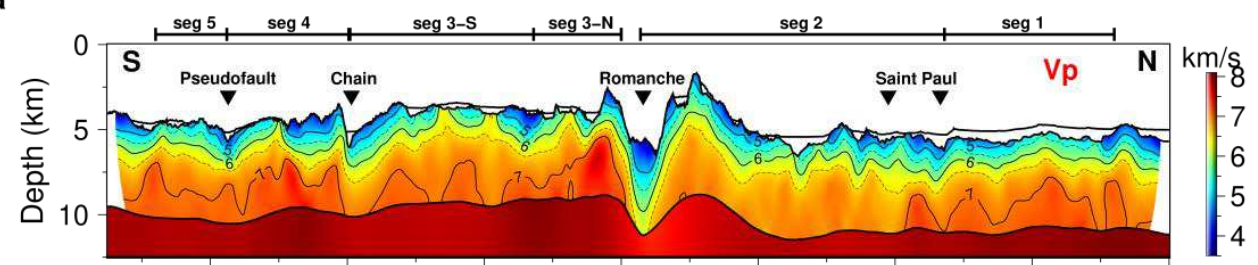

b

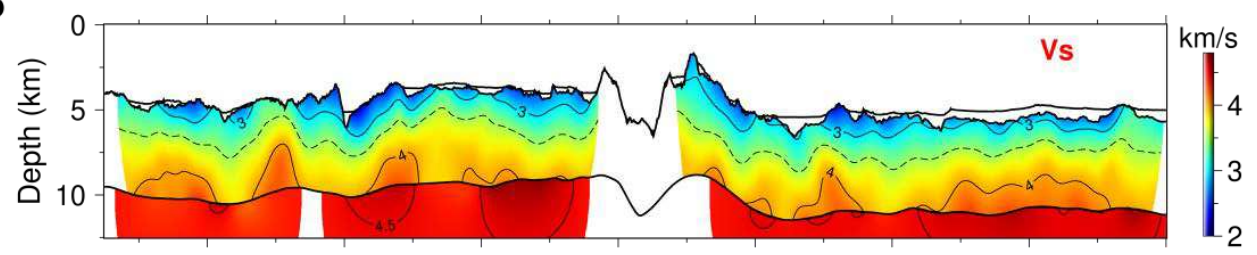

C

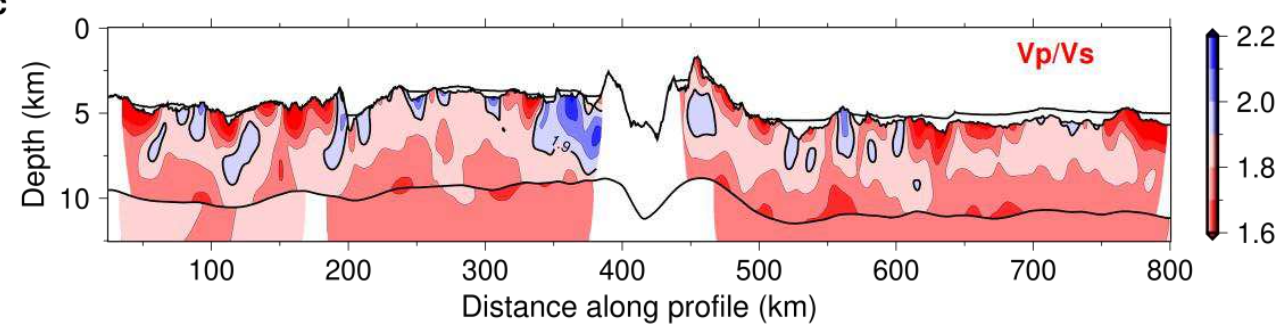

565

566 Fig. 3 Crustal and upper mantle velocity models. Inverted P-wave velocity (Vp) model

567 (a), S-wave velocity (Vs) model (b) and $\mathrm{Vp} / \mathrm{Vs}$ ratio (c). The distance ranges of Segment 5681 to 5 are marked on the top of $\mathbf{a}$. 
a

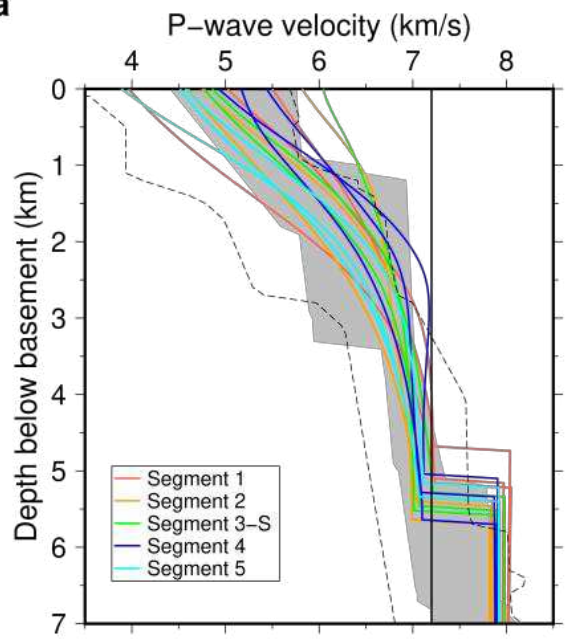

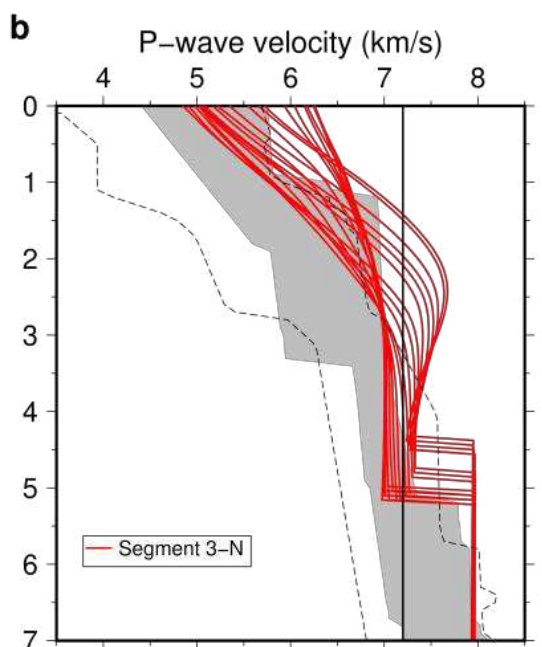

571

572 Fig. 4 One-dimensional P-wave velocity-depth profiles. a, Profiles extracted from the

573 Segments 1, 2, 3-S, 4, 5 with predominantly magmatic accreted crust. b, Profiles

574 extracted from the Segment 3-N with predominantly tectonically formed crust. The black

575 dashed lines represent the velocity envelope for the oceanic crust aged 59-150 Myr in the

576 Atlantic Ocean ${ }^{28}$. The grey shadings represent the velocity envelope for the slow-

577 spreading oceanic crust aged $>7.5 \mathrm{Myr}^{27}$. The black solid lines represent the $7.2 \mathrm{~km} / \mathrm{s}$ 578 velocity.

579 

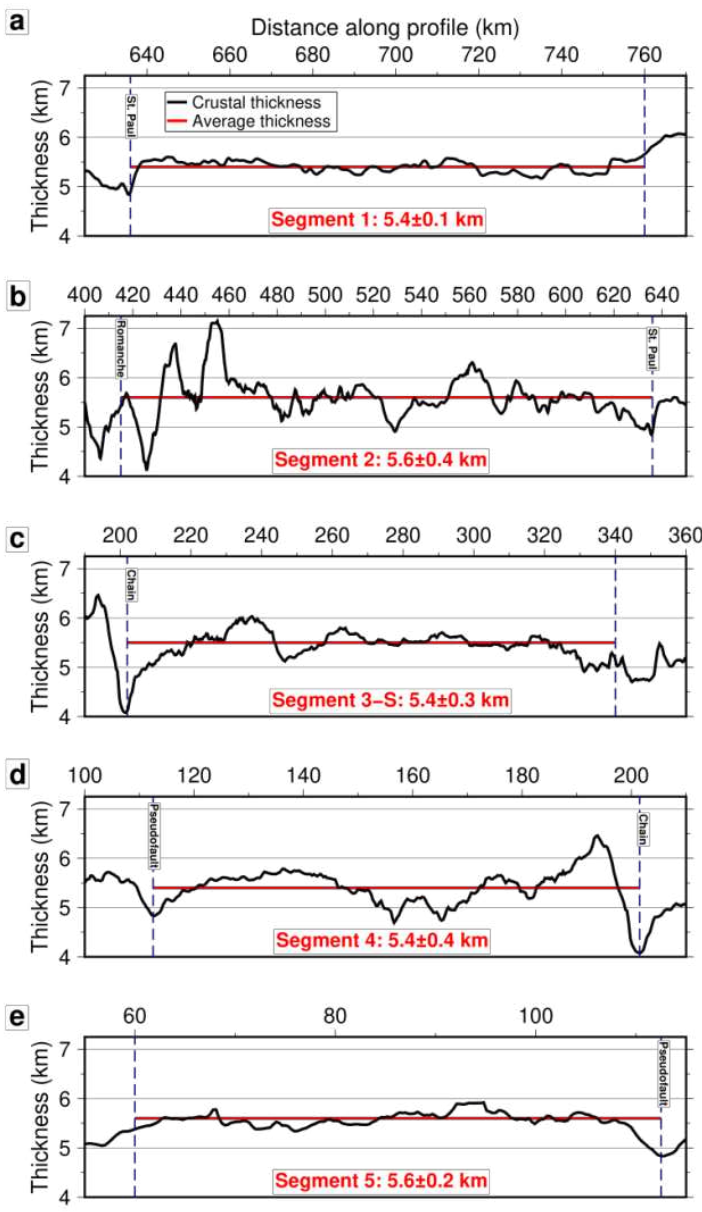

581 Fig. 5 Crustal thickness variation (black curves) and average crustal thickness (red 582 lines) of each ridge segment. The dashed blue lines in each panel indicate the 583 boundaries of ridge segments. The numbers in red show the average crustal thickness and 584 the standard deviation. 


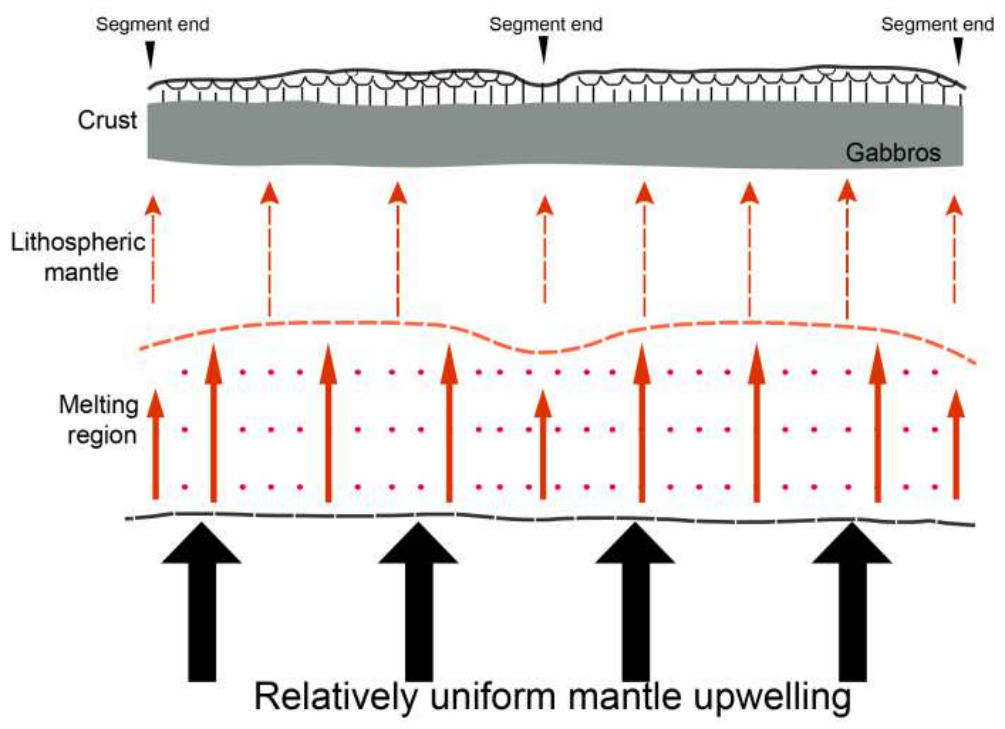

588 Fig. 6 Schematic diagram showing the relatively uniform crustal accretion and the 589 two-dimensional sheet-like mantle upwelling. The black thick arrows represent the 590 mantle flow. The red solid arrows represent the melt migration in the melting region and 591 the red dashed arrows represent the melt migration in the lithospheric mantle. In this 592 model, the melt is not focused to segment centres at the base of the lithosphere ${ }^{19,20}$, but 593 migrates upward vertically. 


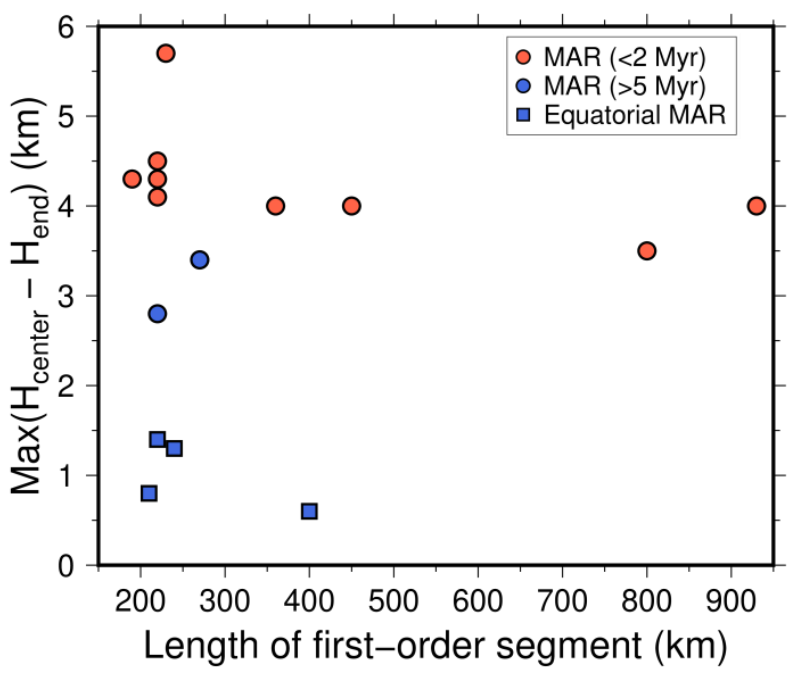

598 Fig. 7 Maximum crustal thickness variation between centres and ends of second599 order ridge segments versus the length of the corresponding first-order ridge 600 segment in the Atlantic Ocean. The crustal thickness constrained by both active-source 601 seismic data and gravity data is considered. Data are given in Supplementary Table 3. 


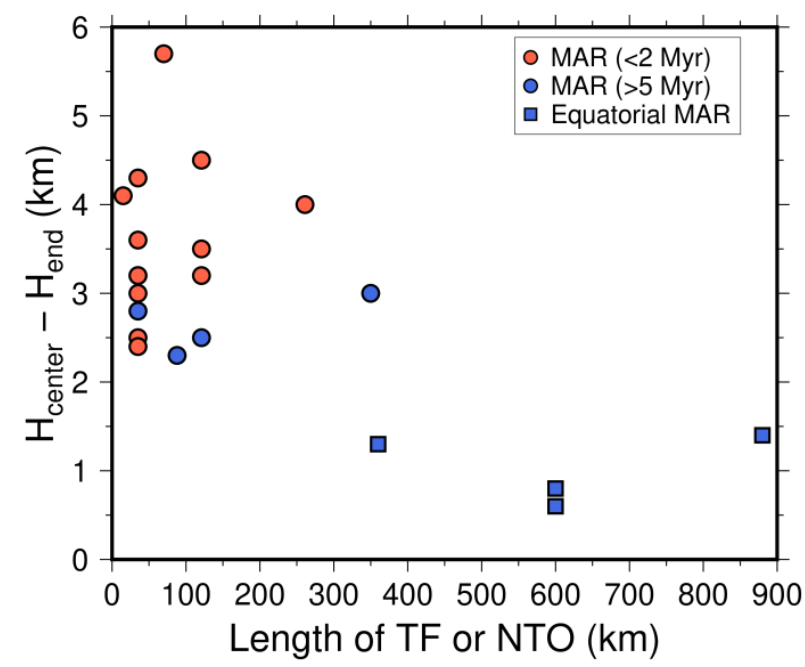

604 Fig. 8 Crustal thinning towards the oceanic TF or NTO in the Atlantic Ocean as a 605 function of the length of TF or NTO. Only the crustal thickness constrained by active606 source seismic data is considered. The blue squares show the crustal thickness reductions 607 at TF, FZ and NTO relative to the average crustal thickness of segments obtained in this 608 study. For a transform fault composed of several intra-transform faults, the total length of 609 the transform fault is used. Data are given in Supplementary Table 4. TF: transform fault; 610 NTO: non-transform offset. 
613 1. Searle, R. Mid-Ocean Ridges (Cambridge University Press, Cambridge, 2013). 17885-17899 (1998).

3. Lin, J. \& Morgan, J. P. The spreading rate dependence of three-dimensional midocean ridge gravity structure. Geophys. Res. Lett. 19, 13-16 (1992).

4. Pablo Canales, J., Detrick, R. S., Toomey, D. R. \& Wilcock, W. S. D. Segmentscale variations in the crustal structure of 150 - $300 \mathrm{kyr}$ old fast spreading oceanic crust (East Pacific Rise, $8^{\circ} 15^{\prime} \mathrm{N}-10^{\circ} 5^{\prime} \mathrm{N}$ ) from wide-angle seismic refraction profiles. Geophys. J. Int. 152, 766-794 (2003).

5. Roland, E., Lizarralde, D., McGuire, J. J. \& Collins, J. A. Seismic velocity constraints on the material properties that control earthquake behavior at the QuebradaDiscovery-Gofar transform faults, East Pacific Rise. J. Geophys. Res. 117, B11102 (2012).

6. Tréhu, A. M. \& Purdy, G. M. Crustal structure in the Orozco Transform Zone. J. Geophys. Res. 89, 1834-1842 (1984).

7. Bell, R. E. \& Buck, W. R. Crustal control of ridge segmentation inferred from observations of the Reykjanes Ridge. Nature 357, 583-586 (1992).

8. Lin, J., Purdy, G. M., Schouten, H., Sempere, J. C. \& Zervas, C. Evidence from gravity data for focused magmatic accretion along the Mid-Atlantic Ridge. Nature 344, 627-632 (1990).

9. Tolstoy, M., Harding, A. J. \& Orcutt, J. A. Crustal Thickness on the Mid-Atlantic Ridge: Bull's-Eye Gravity Anomalies and Focused Accretion. Science 262, 726-729 (1993).

10. Detrick, R. S., Needham, H. D. \& Renard, V. Gravity anomalies and crustal thickness variations along the Mid-Atlantic Ridge between $33^{\circ} \mathrm{N}$ and $40^{\circ} \mathrm{N}$. J. Geophys. Res. 100, 3767-3787 (1995).

11. Kuo, B.-Y. \& Forsyth, D. W. Gravity anomalies of the ridge-transform system in the South Atlantic between 31 and $34.5^{\circ} \mathrm{S}$ : Upwelling centers and variations in crustal thickness. Mar. Geophys. Res. 10, 205-232 (1988).

12. Dunn, R. A., Lekić, V., Detrick, R. S. \& Toomey, D. R. Three-dimensional seismic structure of the Mid-Atlantic Ridge $\left(35^{\circ} \mathrm{N}\right)$ : Evidence for focused melt supply and lower crustal dike injection. J. Geophys. Res. 110, B09101 (2005). 

thickness and structure along three contrasting spreading segments of the Mid-Atlantic

14. Canales, J. P., Detrick, R. S., Lin, J., Collins, J. A. \& Toomey, D. R. Crustal and upper mantle seismic structure beneath the rift mountains and across a nontransform offset at the Mid-Atlantic Ridge ( $35^{\circ}$ N). J. Geophys. Res. 105, 2699-2719 (2000).

15. Dannowski, A., et al. Crustal structure of the propagating TAMMAR ridge segment on the Mid-Atlantic Ridge, $21.5^{\circ}$ N. Geochem. Geophys. Geosyst. 12, Q07012 (2011).

16. Planert, L., Flueh, E. R. \& Reston, T. J. Along- and across-axis variations in crustal thickness and structure at the Mid-Atlantic Ridge at $5^{\circ} \mathrm{S}$ obtained from wideangle seismic tomography: Implications for ridge segmentation. J. Geophys. Res. 114, B09102 (2009).

17. Sinha, M. C. \& Louden, K. E. The Oceanographer fracture zone - I. Crustal structure from seismic refraction studies. Geophys. J. Int. 75, 713-736 (1983).

18. Minshull, T. A., Bruguier, N. J. \& Brozena, J. M. Ridge-plume interactions or mantle heterogeneity near Ascension Island? Geology 26, 115-118 (1998).

19. Magde, L. S. \& Sparks, D. W. Three-dimensional mantle upwelling, melt generation, and melt migration beneath segment slow spreading ridges. J. Geophys. Res. 102, 20571-20583 (1997).

20. Magde, L. S., Sparks, D. W. \& Detrick, R. S. The relationship between buoyant mantle flow, melt migration, and gravity bull's eyes at the Mid-Atlantic Ridge between $33^{\circ} \mathrm{N}$ and $35^{\circ}$ N. Earth Planet. Sci. Lett. 148, 59-67 (1997).

21. Whitmarsh, R. B. \& Calvert, A. J. Crustal structure of Atlantic fracture zones I. The Charlie-Gibbs Fracture Zone. Geophys. J. Int. 85, 107-138 (1986).

22. Davy, R. G., Collier, J. S., Henstock, T. J. \& Consortium, T. V. Wide-Angle Seismic Imaging of Two Modes of Crustal Accretion in Mature Atlantic Ocean Crust. J. Geophys. Res. 125, e2019JB019100 (2020).

23. Minshull, T. A., et al. Crustal structure at the Blake Spur Fracture Zone from expanding spread profiles. J. Geophys. Res. 96, 9955-9984 (1991).

24. Henstock, T. J., White, R. S. \& McBride, J. H. Along-axis variability in crustal accretion at the Mid-Atlantic Ridge: Results from the OCEAN study. J. Geophys. Res. 101, 13673-13688 (1996). 
25. Christeson, G. L., et al. South Atlantic Transect: Variations in Oceanic Crustal Structure at $31^{\circ}$ S. Geochem. Geophys. Geosyst. 21, e2020GC009017 (2020).

26. Cann, J. R., et al. Corrugated slip surfaces formed at ridge-transform intersections on the Mid-Atlantic Ridge. Nature 385, 329-332 (1997).

27. Christeson, G. L., Goff, J. A. \& Reece, R. S. Synthesis of Oceanic Crustal Structure From Two-Dimensional Seismic Profiles. Rev. Geophys. 57, 504-529 (2019).

28. White, R. S., McKenzie, D. \& O'Nions, R. K. Oceanic crustal thickness from seismic measurements and rare earth element inversions. J. Geophys. Res. 97, 1968319715 (1992).

29. Blackman, D. K. \& Collins, J. A. Lower crustal variability and the crust/mantle transition at the Atlantis Massif oceanic core complex. Geophys. Res. Lett. 37, L24303 (2010).

30. Canales, J. P., Dunn, R. A., Arai, R. \& Sohn, R. A. Seismic imaging of magma sills beneath an ultramafic-hosted hydrothermal system. Geology 45, 451-454 (2017).

31. Canales, J. P., Sohn, R. A. \& deMartin, B. J. Crustal structure of the TransAtlantic Geotraverse (TAG) segment (Mid-Atlantic Ridge, $26^{\circ} 10^{\prime} \mathrm{N}$ ): Implications for the nature of hydrothermal circulation and detachment faulting at slow spreading ridges. Geochem. Geophys. Geosyst. 8, Q08004 (2007).

32. Dunn, R. A., Arai, R., Eason, D. E., Canales, J. P. \& Sohn, R. A. ThreeDimensional Seismic Structure of the Mid-Atlantic Ridge: An Investigation of Tectonic, Magmatic, and Hydrothermal Processes in the Rainbow Area. J. Geophys. Res. 122, 9580-9602 (2017).

33. Dannowski, A., et al. Seismic structure of an oceanic core complex at the MidAtlantic Ridge, $22^{\circ} 19^{\prime}$ N. J. Geophys. Res. 115, B07106 (2010).

34. Christensen, N. I. Serpentinites, Peridotites, and Seismology. Int. Geol. Rev. 46, 795-816 (2004).

35. Miller, D. J. \& Christensen, N. I. Seismic velocities of lower crustal and upper mantle rocks form the slow-spreading Mid-Atlantic Ridge, south of the Kane transform zone (MARK). Proc. Ocean Drill. Program Sci. Results 153, 437-454 (1997).

36. Johnston, J. E. \& Christensen, N. I. Seismic properties of layer 2 basalts. Geophys. J. Int. 128, 285-300 (1997).

37. Grevemeyer, I., et al. Episodic magmatism and serpentinized mantle exhumation at an ultraslow-spreading centre. Nature Geosci. 11, 444-448 (2018). 
38. Bonatti, E., et al. Lower Cretaceous deposits trapped near the equatorial Mid-

Atlantic Ridge. Nature 380, 518-520 (1996).

39. Granot, R. \& Dyment, J. The Cretaceous opening of the South Atlantic Ocean. Earth Planet. Sci. Lett. 414, 156-163 (2015).

40. Müller, R. D., Sdrolias, M., Gaina, C. \& Roest, W. R. Age, spreading rates, and spreading asymmetry of the world's ocean crust. Geochem. Geophys. Geosyst. 9, Q04006 (2008).

41. Dick, H. J. B., Lin, J. \& Schouten, H. An ultraslow-spreading class of ocean ridge. Nature 426, 405-412 (2003).

42. Growe, K., et al. Seismic structure of the St. Paul Fracture Zone and Late Cretaceous to Mid Eocene oceanic crust in the equatorial Atlantic Ocean near $18^{\circ} \mathrm{W} . J$. Geophys. Res. 126, e2021JB022456 (2021).

43. Matthews, K. J., Müller, R. D., Wessel, P. \& Whittaker, J. M. The tectonic fabric of the ocean basins. J. Geophys. Res. 116, B12109 (2011).

44. Gregory, E. P. M., Singh, S. C., Marjanović, M. \& Wang, Z. Serpentinized peridotite versus thick mafic crust at the Romanche oceanic transform fault. Geology 49, 1132-1136 (2021).

45. Marjanović, M., et al. Seismic Crustal Structure and Morpho-tectonic Features Associated with the Chain Fracture Zone and their Role in the Evolution of the Equatorial Atlantic Region. J. Geophys. Res. 125, e2020JB020275 (2020).

46. Van Avendonk, H. J. A., Shillington, D. J., Holbrook, W. S. \& Hornbach, M. J. Inferring crustal structure in the Aleutian island arc from a sparse wide-angle seismic data set. Geochem. Geophys. Geosyst. 5, Q08008 (2004).

47. Vaddineni, V. A., Singh, S. C., Grevemeyer, I., Audhkhasi, P. \& Papenberg, C. Evolution of the Crustal and Upper Mantle Seismic Structure From 0-27 Ma in the Equatorial Atlantic Ocean at $2^{\circ} \quad 4^{\prime}$ S. J. Geophys. Res. 126, e2020JB021390 (2021).

48. Maia, M., Brunelli, D. \& Party, t. S. C. S. The Eastern Romanche ridge-transform intersection (Equatorial Atlantic): slow spreading under extreme low mantle temperatures. Preliminary results of the SMARTIES cruise. EGU General Assembly 2020, (2020).

49. Hicks, S. P., et al. Back-propagating supershear rupture in the $2016 \mathrm{Mw} 7.1$ Romanche transform fault earthquake. Nature Geosci. 13, 647-653 (2020).

50. Grevemeyer, I., Weigel, W. \& Jennrich, C. Structure and ageing of oceanic crust at $14^{\circ} \mathrm{S}$ on the East Pacific Rise. Geophys. J. Int. 135, 573-584 (1998). 
51. Van Avendonk, H. J. A., Harding, A. J., Orcutt, J. A. \& McClain, J. S. Contrast in crustal structure across the Clipperton transform fault from travel time tomography. $J$. Geophys. Res. 106, 10961-10981 (2001).

52. Escartín, J., et al. Quantifying tectonic strain and magmatic accretion at a slow spreading ridge segment, Mid-Atlantic Ridge, 29² N. J. Geophys. Res. 104, 10421-10437 (1999).

53. Combier, V., et al. Three-dimensional geometry of axial magma chamber roof and faults at Lucky Strike volcano on the Mid-Atlantic Ridge. J. Geophys. Res. 120, 5379-5400 (2015).

54. Shaw, P. R. Ridge segmentation, faulting and crustal thickness in the Atlantic Ocean. Nature 358, 490-493 (1992).

55. Escartín, J. \& Lin, J. Ridge offsets, normal faulting, and gravity anomalies of slow spreading ridges. J. Geophys. Res. 100, 6163-6177 (1995).

56. Grevemeyer, I., Rüpke, L. H., Morgan, J. P., Iyer, K. \& Devey, C. W. Extensional tectonics and two-stage crustal accretion at oceanic transform faults. Nature 591, 402407 (2021).

57. Harmon, N., et al. Marine Geophysical Investigation of the Chain Fracture Zone in the Equatorial Atlantic From the PI-LAB Experiment. J. Geophys. Res. 123, 1101611030 (2018).

58. Bunch, A. W. H. \& Kennett, B. L. N. The crustal structure of the Reykjanes Ridge at $59^{\circ} 30^{\prime}$ N. Geophys. J. Int. 61, 141-166 (1980).

59. Schilling, J.-G., Hanan, B. B., McCully, B., Kingsley, R. H. \& Fontignie, D. Influence of the Sierra Leone mantle plume on the equatorial Mid-Atlantic Ridge: A NdSr-Pb isotopic study. J. Geophys. Res. 99, 12005-12028 (1994).

60. Schilling, J.-G., et al. Thermal structure of the mantle beneath the equatorial MidAtlantic Ridge: Inferences from the spatial variation of dredged basalt glass compositions. J. Geophys. Res. 100, 10057-10076 (1995).

61. Fox, P. J. \& Gallo, D. G. A tectonic model for ridge-transform-ridge plate boundaries: Implications for the structure of oceanic lithosphere. Tectonophysics 104, 205-242 (1984).

62. Behn, M. D., Boettcher, M. S. \& Hirth, G. Thermal structure of oceanic transform faults. Geology 35, 307-310 (2007). 
840 63. Rychert, C. A., et al. A dynamic lithosphere-asthenosphere boundary near the 841 equatorial Mid-Atlantic Ridge. Earth Planet. Sci. Lett. 566, 116949 (2021).

64. Harmon, N., et al. Evolution of the Oceanic Lithosphere in the Equatorial Atlantic From Rayleigh Wave Tomography, Evidence for Small-Scale Convection From the PILAB Experiment. Geochem. Geophys. Geosyst. 21, e2020GC009174 (2020).

65. Bonatti, E., Seyler, M. \& Sushevskaya, N. A Cold Suboceanic Mantle Belt at the Earth's Equator. Science 261, 315-320 (1993).

66. Escartín, J., et al. Central role of detachment faults in accretion of slow-spreading oceanic lithosphere. Nature 455, 790-794 (2008).

67. Kim, E., et al. Upper Crustal Vp/Vs Ratios at the Endeavour Segment, Juan de Fuca Ridge, From Joint Inversion of $\mathrm{P}$ and $\mathrm{S}$ Traveltimes: Implications for Hydrothermal Circulation. Geochem. Geophys. Geosyst. 20, 208-229 (2019).

68. Moser, T. J. Shortest path calculation of seismic rays. Geophysics 56, 59-67 (1991).

69. Toomey, D. R. \& Foulger, G. R. Tomographic inversion of local earthquake data from the Hengill-Grensdalur Central Volcano Complex, Iceland. J. Geophys. Res. 94, 17497-17510 (1989).

70. Korenaga, J., et al. Crustal structure of the southeast Greenland margin from joint refraction and reflection seismic tomography. J. Geophys. Res. 105, 21591-21614 (2000). 


\section{Acknowledgements}

871 We are grateful to the officers, crew, and scientific technicians of the 2018 ILAB-SPARC

872 cruise for their hard work. The research leading to these results has received funding

873 from the European Research Council under the European Union's Seventh Framework

874 Programme (FP7/2007-2013)/ ERC Advance Grant no. 339442 TransAtlanticILAB.

875 Zhikai appreciates Milena Marjanović, Emma P. M. Gregory, Mathilde Cannat, Venkata

876 Vaddineni, Kevin Growe and Jie Chen for their help and useful discussions. Some results

877 presented in this paper are performed on the S-CAPAD platform of Institut de Physique

878 du Globe de Paris, France.

879

\section{Author contributions}

881 Z.W. processed and analysed the OBS data and wrote the paper. S.C.S. developed the 882 project, led the data acquisition and supervised the data processing, interpretation and 883 writing.

\section{Competing interests}

886 The authors declare no competing interests.

\section{Data availability}

889 The high-resolution bathymetry data, the multichannel seismic reflection data and the 890 OBS data from the OBS26 to OBS50 are available online 891 (https://doi.pangaea.de/10.1594/PANGAEA.922331) under the condition of 892 acknowledging Marjanović et al., 2020. The OBS data from the OBS01 to OBS15 are 893 available online (https://doi.pangaea.de/10.1594/PANGAEA.937195) under the condition 894 of acknowledging Growe et al., 2021. The OBS data from the OBS16 to OBS25 will be 895 available on request from the authors after the publication of this paper. 


\section{Supplementary Files}

This is a list of supplementary files associated with this preprint. Click to download.

- Supplementaryinformation.pdf 